\title{
Chemical Analysis of Urinary Stones
}

\author{
Ghanshyam Sigdel, Nirml Lamichhane, K.C SR, Belokar W.K \\ Department of Urology, College of Medical Sciences, Chitwan, Nepal \\ Correspondence: Dr. Ghanshyam Sigdel, Department of Urology, College of Medical Sciences Teaching Hospital, \\ Chitwan, Nepal \\ E-mail: sigdelgs@yahoo.com
}

\begin{abstract}
Introduction: Urinary stone disease is a common urological problem. Chemical analysis of the urinary stones is a part of metabolic evaluation of first time or recurrent stone formers. The report of chemical analysis of stones may obviate the need for complete metabolic evaluation or can direct metabolic evaluation. In this study we aim to find out the chemical compositions of urinary stones in our population, so that the result might serve as a baseline for the related research in future.

Methods: A prospective study was carried out in our institute with the qualitative chemical analysis of urinary stones. All patients operated for different urinary stones by various methods were included in the study. Statistical analysis was done by using Statistical Package for the Social Sciences Software (SPSS) Program for windows ${ }^{\circledR}$ version 18.

Results: A total of 55 patients were included in the study. Male to female ratio was 1.75 . Mean age was 41.45 years. Ureteric and renal stones were most common accounting to 49 and 31 percentage respectively. All stones contained calcium. Calcium, phosphate, oxalate and uric acid were the major constituents of the stones representing 100, 94.5, 85.5 and 80 percentage of the stone specimen. Other constituents were amino acids, carbonate, magnesium and cystine.

Conclusions: Urinary stones are of mixed chemical compositions. Further large scale prospective studies along with other parameters of metabolic work up are recommended to know more about the chemical compositions of urinary stones and its utility in clinical practice.
\end{abstract}

Key words: chemical analysis; urinary stones.

\section{Introduction}

Urinary tract stone disease is a common urological problem worldwide. Clinical presentations and chemical compositions of urinary stones have wide range of variations. Stone analysis provides an opportunity for better understanding of the physico-chemical principles of stone formation and may improve the accuracy of metabolic evaluation. The main types of stones are made up of calcium oxalate, calcium phosphate, magnesium, ammonium, phosphate and uric acid. There are several methods of urinary stone analysis. Physical methods of stone analysis include optical crystallography, $\mathrm{x}$ - ray diffraction, infrared spectroscopy, $\mathrm{x}$ - ray spectroscopy and thermogravimetry. These methods require elaborate apparatus, are generally only semi quantitative and do not detect minor constituents of mixed calculi. ${ }^{1}$ Chemical analysis is a convenient procedure for routine use. The method is relatively rapid will detect minor components of mixed calculi and can readily be made quantitative. ${ }^{2}$

\section{Methods}

We conducted a prospective study to find out the chemical compositions of urinary stones in our population. Urinary tract stones removed by various methods from different anatomical locations were included in the study. Whole or a piece of the removed stone was kept in normal saline and sent to biochemistry laboratory for the qualitative chemical analysis for various possible chemical compositions. The 
stones were first ground into a fine powder and subsequently analysed by standard chemical methods. Basically stones were analysed for Calcium (Ca), Oxalate (Ox), Phosphate (PO4), Urate (UA), Magnesium (Mg), Carbonate (CO3), and Cystine (Cys) and Amino acids(AA) other than Cystine.

Statistical analytsis was done by using Statistical Package for the Social Sciences Software (SPSS) Program for windows ${ }^{\circledR}$ version 18 .

\section{Results}

A total of 55 patients treated for urinary stone disease were included in the study. There was male preponderance with male to female ratio of 1.75 (Table 1). Ureteric and renal stones were most common accounting to 49 and 31 percentage respectively. Calcium was present in all the stones. Majority of the stones contain Calcium, Phosphate, Oxalate and Uric acid representing 100, 94.5, 85.5 and 80 percentage of the stone specimen (Table 2). Other constituents were Amino acids, Carbonate, Magnesium and Cystine. Stones were of mixed composition with dominance of calcium phosphate and calcium oxalates (Table 3).

Table 1: Demographics and stone related variables

\begin{tabular}{ll}
\hline Variable(s) & Values \\
Total number of patients & 55 \\
Gender (Male/female) & $35 / 20(63.6 / 36.4 \%)$ \\
Age in years* & $41.45 \pm 17.218(6--86)$ \\
Site of stones, $N(\%)$ & \\
Kidney & $17(30.9)$ \\
Ureter & $27(49.1)$ \\
Bladder & $9(16.4)$ \\
Urethra & $2(3.6)$ \\
Surgical procedures, $N(\%)$ & \\
Pylolithotomy & $13(23.6)$ \\
Nephrolithotomy & $3(5.5)$ \\
PCNL & $1(1.8)$ \\
Ureterolithotomy & $21(38.2)$ \\
URS & $6(10.9)$ \\
Cystolitholapaxy & $6(10.9)$ \\
Cystolithotomy & $5(9.1)$ \\
\hline
\end{tabular}

$*$ Mean \pm SD (range)
Table 2 Distribution of chemicals in 55 stones

$\begin{array}{ll}\text { Substance } & \text { Frequency (Percentage) } \\ \text { Calcium } & 55(100) \\ \text { Phosphate } & 52(94.5) \\ \text { Oxalate } & 47(85.5) \\ \text { Uric Acid } & 44(80) \\ \text { Carbonate } & 12(21.8) \\ \text { Amino Acid* } & 5(9.1) \\ \text { Magnesium } & 7(12.7) \\ \text { Cystine } & 6(10.9)\end{array}$

* Amino acids other than cystine

\section{Table 3 Stone composition}

\begin{tabular}{|c|c|}
\hline Stone composition & Frequency( Percentage) \\
\hline $\mathrm{CaOxPO}_{4} \mathrm{UA}$ & $18(32.7)$ \\
\hline $\mathrm{CaPO}_{4} \mathrm{UA}$ & $9(16.4)$ \\
\hline $\mathrm{CaOxPO}_{4} \mathrm{UACO}_{3}$ & $8(14.5)$ \\
\hline $\mathrm{CaOxPO}_{4} \mathrm{UAC}$ Cys & $3(5.5)$ \\
\hline $\mathrm{CaOxPO}_{4} \mathrm{UACO}_{3} \mathrm{AA}$ & $2(3.6)$ \\
\hline $\mathrm{CaOxPO}_{4} \mathrm{Mg}$ & $2(3.6)$ \\
\hline $\mathrm{CaOxPO}_{4} \mathrm{UAMg}$ & $2(3.6)$ \\
\hline $\mathrm{CaOxUA}$ & $2(3.6)$ \\
\hline $\mathrm{CaOxMg}$ & $1(1.8)$ \\
\hline $\mathrm{CaOxPO}_{4} \mathrm{AA}$ & $1(1.8)$ \\
\hline $\mathrm{CaPO}_{4} \mathrm{AAUA}$ & $1(1.8)$ \\
\hline $\mathrm{CaPO}_{4} \mathrm{UAMg}$ & $1(1.8)$ \\
\hline $\mathrm{CaOxPO}_{4} \mathrm{AAUA}$ & $1(1.8)$ \\
\hline $\mathrm{CaPO}_{4} \mathrm{UACys}$ & $1(1.8)$ \\
\hline $\mathrm{CaPO}_{4} \mathrm{CO}_{3}$ & $1(1.8)$ \\
\hline $\mathrm{CaOxPO}_{4} \mathrm{Cys}$ & $1(1.8)$ \\
\hline $\mathrm{CaOxPO}_{4} \mathrm{UAMgCysCO}_{3}$ & $1(1.8)$ \\
\hline
\end{tabular}




\section{Discussion}

The lifetime prevalence of urinary stone disease is estimated at $1 \%$ to $15 \%$, with the probability of having a stone varying according to age, gender, race, and geographic location. ${ }^{3}$ Formation of a urinary stone disease is a complex, multifactorial process with very high recurrence rate of up to fifty percent. Therefore an isolated information in the form of clinical context, biochemical reports, imaging studies or chemical compositions of the stone is not sufficient to guide the treatment and prevent recurrence, rather requires a correlation among them. Knowledge of chemical compositions of the urinary stones mainly helps to guide measures that can be taken to prevent stone recurrence.

There are various methods to analyze the chemical compositions of the urinary stones. Physical methods such as infrared spectroscopy, X-ray diffractometry and solid state nuclear magnetic resonance spectroscopy have the advantages of determining the structures of the stones. $^{4-6}$ However, the technology is costly, needs high technical skills and moreover they are generally only semi quantitative and do not detect minor constituents of mixed calculi. ${ }^{1}$ The chemical analytic technique detects the individual ions. It is much cheaper, readily available and can be qualitative or quantitative. A simple qualitative chemical method was used here to determine the chemical composition of the urinary stones.

Calcium is the most common inorganic constituent of urinary stones, which varies according to the study population from different places. It was present in all stones in our series. The percentages of Calcium have been reported varying from 76.9 to 100 in other series. ${ }^{7-9}$ There were $52(94.5 \%)$ stones which contained Phosphate (PO4). It was the second most common inorganic compound in the current analysis which was higher than those reported by other studies. ${ }^{9}$ Oxalate was the third most common constituent of the stones, that represented $85.5 \%$ which was higher than that reported from the University Hospital of the West Indies but lower than those reported from Nepal. ${ }^{8,9}$ The percentage composition of urate has been generally quoted between 16-37\%, however we had 44 ( $80 \%$ ) of the stones containing uric acid..$^{7-10}$

Carbonate is not a common constituent of the urinary stone. We detected Carbonate in $12(21.8 \%)$ of the stones. All the stones were of mixed variety with $\mathrm{CaOxPO}_{4} \mathrm{UA}$ being the most common composition (Table 3). Interestingly there was one stone, which contained $\mathrm{CaOxPO}_{4} \mathrm{UAMgCysCO}_{3}$.

This study had some limitations. Ammonium (NH4), which is one of the common constituents of the urinary stones was not analyzed due to technical difficulties. So we are not aware of the distribution of ammonium containing stone in our populations. Secondly, the stone analysis reports were neither correlated with the 24 hour urinary level of related chemical substances nor urinary supersaturates. In the absence of such collective information it's difficult to manage patients, only on the basis of stone analysis.

\section{Conclusion}

Urinary stones are of mixed chemical composition. However, further metabolic evaluations are necessary for clinical correlation.

\section{References}

1. Pollack SS, Carlson GL. A comparison of X-ray diffraction and infrared technics for indentifying kidney stones. Amer JClin Pathol.1969;52: 656-60. https://doi.org/10.1093/ajcp/52.6.656

2. Hodgkinson. A combined qualitative and quantitative procedure for the chemical analysis of urinary calculi. J ClinPathol.1971;24: 147-51. https://doi.org/10.1136/jep.24.2.147

3. Wein AJ, Kavoussi LR, Novick AC, et al . CampbellWalsh Urology 10th edition Philadelphia, Elsevier Saunders.2012: Page 1257.

4. Rebentisch G, Berg W. Comparison of methods and guaranteeing quality of urinary calculi -5 th international ring test. Urol Int.1989;44: 298-302. https://doi.org/10.1159/000281526 PMid:2800065

5. Leusman DB, Blaschke R, SchmandtW. Results of 5035 stone analyses:a contribution to epidemiology of urinary stone disease. Scand JUrol Nephrol.1990; 24: 205-10. https://doi.org/10.3109/00365599009180859

6. Bak M, Thomsen JK, Jakobsen HJ, Petersen SE, Petersen TE, Nielsen NC. Solid-State 13C and 31PNMR analysis of urinary stones. J Uro.2000;164: 856-63. https://doi.org/10.1016/S0022-5347(05)67327-2

7. Mshelia DS, Gali BM, Naaya UH, Habu SA. Chemical composition of urinary calculi in Maiduguri, Nigeria. Afr J Med Med Sci.2005;34: 185-8. PMid:16749345

8. Choo-Kang E.Chemical composition of urinary tract stones at the University Hospital of the West Indies. West Indian Med J.2008;57: 427-30. PMid: 19565970

9. Risal S, Risal P, Pandeya DR et al. Spectrum of stones composition: a chemical analysis of renal stones of patients visiting NMCTH. Nepal Med Coll J.2006;8: 263-5. PMid:17357646 